\title{
METABOLIC SYNDROME INPATIENTS WITH RHEUMATOID ARTHRITIS
}

\author{
Ali Mahmoud Kasem, MD*; Esam Mohammed Abo Al-Fadl, MD**; Hanan \\ Sayed Mohammed Abo-Zeid, MD**; Ebtesam Khalaf Ali Fayez, MSc**. \\ * Department of Internal Medicine- Faculty of Medicine- Sohag University; ** Department of \\ Rheumatology, Rehabilitation and Physical medicine - Faculty of Medicine- Sohag \\ University.
}

\section{ABSTRACT}

Objectives:To determine the prevalence of metabolic syndrome (MetS) in patients with rheumatoid arthritis (RA) and to evaluate the relation between parameters of MetS and clinical aspects of RA.

Design: Cross-sectional study.

Patients:Patients with rheumatoid arthritis (RA) according to 2010 ACR/EULAR classification criteria for RA $(n=150)$.

Methods: Demographic data, arthritis history, medical and therapeutic history were evaluated. Height, weight, BMI, waist circumference (WC) and blood pressure (BP) were recorded. Disease activity was evaluated using DAS28 (ESR). Immunological investigations included RF, ESR, CRP, and anti-CCP. Fasting blood glucose and lipid profile were measured.The patient was diagnosed as having MetS according to 3 definitions; ATPIII (2004), IDF (2005), and JIS (2009).

Results:Prevalence of MetS in rheumatoid patients was 48\% (ATPIII definition), 52 $\%$ (IDF definition), and $46 \%$ (JIS definition with Egyptian cut-off of WC), respectively. The most prevalent component of MetS was central obesity (75.3- $92 \%$ according to the used definition).DAS28 was significantly higher in patients with MetS with higher number of tender joints and VAS (0-100) and most rheumatoid patients with MetS (68\%) had high disease activity.

Conclusions:The increased prevalence of MetS components in RA patients, suggests greater attention be given to modifiable risk factors, including improvement of dietary habits, physical activity and blood pressure control.

Key words: rheumatoid arthritis, metabolic syndrome, DAS28.

\section{INTRODUCTION:}

immune complexes, and altered lipid particle that increase endothelial activation and potentially render atheromatous plaques unstable ${ }^{(4)}$.

Metabolic syndrome (MetS) is multiplex risk factor for type 2 diabetes and CVDs, including insulin resistance, abdominal obesity, atherogenic dyslipidemia, high blood pressure (BP), impaired fasting blood glucose (FBG), a pro-thrombotic state, and a pro-inflammatory state ${ }^{(5)}$.MetS is responsible for a three-fold increase in the risk of atherosclerotic CVDs and increased mortality from CVD, as well

\begin{abstract}
Rheumatoid arthritis (RA) is one of the most prevalent chronic inflammatory diseases. It primarily involves the joints, but should be considered a syndrome that includes extra-articular manifestations, such as rheumatoid nodules, pulmonary involvement or vasculitis, and systemic comorbidities ${ }^{(\mathbf{1})}$. RA is the most common inflammatory arthritis (2). RA is associated with increased rates of cardiovascular diseases (CVD) (3). Circulating inflammatory pathways that are implicated in this risk include cytokines, acute phase reactants,
\end{abstract}


Demographic data (age, sex, residency, occupation and smoking) were obtained from all participants. Arthritis history including age at onset, disease course and duration, and morning stiffness was recorded. Medical history (DM, hypertension, CVDs, respiratory, renal and hepatic diseases) was documented for all patients. Therapeutic history (NSAIDs, DMARDs, glucocorticoid use, cardiovascular drugs, and hypoglycemic drugs) was discussed with all patients.

Height and weight were measured using standard equipments and methods. The body mass index (BMI) was calculated as $\left(\mathrm{kg} / \mathrm{m}^{2}\right)$. The WC was measured in the standing position using a non-stretchable tape, placed directly on skin, at end of expiration at midway between lower costal margin and upper border of iliac crest. Arterial BP measurement was done using a calibrated sphygmomanometer.

\section{II- Joint examination and disease activity:}

Examination of 28 joints of the hands, wrists, elbows, shoulders, and knees was done with count of the swollen and tender joints to calculate DAS28. The disease activity was evaluated using DAS28 (ESR) according to the equation [DAS28 $(E S R)=0.56 \times \sqrt{ }($ TJC 28$)+0.28 \sqrt{ }$ $(\mathrm{SJC} 28)+0.70 \times \ln (\mathrm{ESR})+0.014 \times$ $\mathrm{GH}$ (range, 0-9)]. High disease activity was considered as DAS28>5.1, moderate as DAS28 > 3.2- $\leq 5.1$, and low disease activity in the range 2.63.2. DAS $28 \leq 2.6$ indicated disease remission ${ }^{(13)}$.

III- Laboratory investigations:

\section{III.A) Immunological tests:}

1-Rheumatoid factor ( $\boldsymbol{R F})$ : It was measured in patients' sera by rapid latex agglutination test using AVITEX RF kit (Omega diagnostics LTD, Scotland, United Kingdom).Positive as all-causes, compared to the general population ${ }^{(6)}$.

RA and MetS are considered to be diseases with common traits that can increase the risk of CVDs ${ }^{(7)}$, with previous research showing an association between the two ${ }^{(\mathbf{8})}$. RA is associated with various components of MetS, which increase CVD mortality (9). The frequency of MetS in RA patients ranges from 14 to $56 \%{ }^{(10)}$.

It was found that the risk of having a moderate-to-severe RA was higher in patients with MetS than in those without and that the disease activity correlated with the number of MetS parameters present ${ }^{(11)}$. This study was designed to determine the prevalence of MetS in patients with RA and to evaluate the relation between parameters of MetS and clinical aspects of RA.

\section{PATIENTS AND METHODS:}

This study included 150patients patients; diagnosed as having RA according to the 2010 ACR/EULAR classification criteria forRA (12); attending Rheumatology clinics at Sohag University Hospitals. The study was approved by Ethical and Research committees at Faculty of Medicine, Sohag University. All patients assigned an informed written consent.

\section{Exclusion criteria:}

1. Patients with other inflammatory diseases.

2. Patients with malignancies.

3. Patients with chronic kidney disease.

4. Patients with chronic liver disease.

5. Patients with familial dyslipidemia or diseases known to cause dyslipidemia e.g. hypothyroidism, nephrotic syndrome.

6. Female patients on oral contraceptive pills and pregnant patients.

Methods: Patients were evaluated as follow:

I-Initial evaluation: 
- Raised TG: $\geq 150 \mathrm{mg} / \mathrm{dL}$, or specific treatment for this lipid abnormality.

- Reduced HDL-C: < $40 \mathrm{mg} / \mathrm{dL}$ in males, $<50 \mathrm{mg} / \mathrm{dL}$ in females.

- Raised BP: systolic BP $\geq 130$ or diastolic $\mathrm{BP} \geq 85 \mathrm{~mm} \mathrm{Hg}$, or treatment of previously diagnosed hypertension.

- Raised FBG: $\geq 100 \mathrm{mg} / \mathrm{dL}$, or previously diagnosed T2D.

IV.2- IDF (2005): The presence of central obesity (WC $\geq 94 \mathrm{~cm}$ for men, WC $\geq 80 \mathrm{~cm}$ for women) with any two of the following ${ }^{(15)}$ :

- Raised TG: $\geq 150 \mathrm{mg} / \mathrm{dL}$, or specific treatment for this lipid abnormality.

- Reduced HDL-C: $<40 \mathrm{mg} / \mathrm{dL}$ in males, < $50 \mathrm{mg} / \mathrm{dL}$ in females, or specific treatment for this lipid abnormality.

- Raised BP: systolic BP $\geq 130$ or diastolic $\mathrm{BP} \geq 85 \mathrm{~mm} \mathrm{Hg}$, or treatment of previously diagnosed hypertension.

- Raised FBG: $\geq 100 \mathrm{mg} / \mathrm{dL}$, or previously diagnosed T2D.

IV.3- JIS definition (2009): The presence any three of the following (16).

- Obesity: with the Egyptian cut-off values of WC (100.5 and $96.25 \mathrm{~cm}$ for men and women, respectively) (17)

- Raised TG: $\geq 150 \mathrm{mg} / \mathrm{dL}$, or specific treatment for this lipid abnormality.

- Reduced HDL-C: $<40 \mathrm{mg} / \mathrm{dL}$ in males, < $50 \mathrm{mg} / \mathrm{dL}$ in females, or specific treatment for this lipid abnormality.

- Raised BP: systolic BP $\geq 130$ or diastolic $\mathrm{BP} \geq 85 \mathrm{~mm} \mathrm{Hg}$, or treatment of previously diagnosed hypertension.

- Raised FBG: $\geq 100 \mathrm{mg} / \mathrm{dL}$, or previously diagnosed T2D. results were considered at $\mathrm{RF}$ serum concentration above $8 \mathrm{IU} / \mathrm{ml}$.

2- Erythrocyte Sedimentation Rate (ESR): ESR was measured in the anticoagulated blood of the patients by Wintrobe's method. The reference range of first hour ESR was 3-5 mm/hr (for females) and 7-12 $\mathrm{mm} / \mathrm{hr}$ (for males).

3- C-reactive protein $(C R P)$ : It was measured in patients' sera by rapid latex agglutination test using AVITEX CRP kit (Omega Diagnostics LTD, Scotland, United Kingdom).Positive results were considered at CRP serum concentration above $6 \mathrm{mg} /$ Litre.

4- Anti-cyclic citrullinated peptides (Anti-CCP):was measured by a chemiluminescent microparticle immunoassay using ARCHITECT Anti-CCP Reagent Kit "1P65" (AxisShield Diagnostics LTD, Dundee, United Kingdom). Values more than 5 $\mathrm{IU} / \mathrm{ml}$ were considered positive.

III.B) Fasting blood glucose (FBG): was measured in patients' sera using Glucose HK reagent on Cobas C311 analyzer (Roche Diagnostics $\mathrm{GmbH}$, Germany). The reference range was $70-110 \mathrm{mg} / \mathrm{dl}$.

III.C) Lipid profile:Serum total cholesterol (TC), high density lipoprotein (HDL-C) and triglycerides (TG) were assessed by enzymatic colorimetric methods using commercially available kits on Cobas C311 analyzer (Roche Diagnostics $\mathrm{GmbH}$, Germany).TC between 50 and $200 \mathrm{mg} / \mathrm{dl}$, TG between 40 and 150 $\mathrm{mg} / \mathrm{dl}$, HDL-C more than $35 \mathrm{mg} / \mathrm{dl}$ and LDL-C less than $110 \mathrm{mg} / \mathrm{dl}$ were considered normal values.

IV- Diagnosis of metabolic syndrome (MetS):

The patient was diagnosed as having MetS according to 3 definitions:

IV.1- ATPIII (2004): The presence any three of the following ${ }^{(14)}$ :

- Central obesity: WC $\geq 102 \mathrm{~cm}$ for men, or WC $\geq 88 \mathrm{~cm}$ for women. 
(SPSS, version 24).Qualitative variables were recorded as frequencies and percentages and were compared by chi-square test.Quantitative variables were presented as means \pm standard deviation (SD)for normally distributed data and median with interquartile range (IQR) for non-normally distributed dataand were compared by independent $t$-test. $P$ value $<0.05$ was considered statistically significant.
The 3 definitions were used to calculate only the prevalence. To compare demographic, clinical and laboratory findings between the group of patients with RA and MetS versus RA patients without MetS, we used the MetS rate calculated by JIS (2009).

\section{V- Statistical analysis:}

Data were recorded in Excel data sheet and analyzed usingStatistical Package for Social Sciences soft ware program

\section{RESULTS}

The mean age \pm SD of the patients was $45.01 \pm 11.05$ years, with $126(84 \%)$ of themwere females, and $102(68 \%)$ were from rural areas.Only $17(11.3 \%)$ of the patients were smokers. The mean $\pm \mathrm{SD}$ age at the disease onset of the study population was $35.66 \pm 10.60$ years. The mean \pm SD duration of the disease was $9.60 \pm 7.35$ years. The course of the disease was progressive in all patients. Morning stiffness was recorded in $77(51.3 \%)$ of the study population.

History of hypertension was found in $28(18.7 \%)$ of the study population and DM was documented in $19(12.7 \%)$. History of CVDs was found in $4(2.7 \%)$ of the study population; with history of ischemia in 3 patients and history of myocardial infarction in one patient. History of stroke was found in 1 patient $(0.7 \%)$.

History of use of NSAIDs was found in $146(97.3 \%)$ of the study population. Use of steroids (prednisone/ prednisolone) was demonstrated in 61 (40.7\%). Regarding DMARDs; most patients (61.3\%) were using two drugs. Hydroxychloroquinewas used by $112(74.7 \%)$, methotrexate by 106 (70.7\%),leflunomideby 46(30.7\%), and sulfasalazine by $31(20.7 \%)$ of the study population.The main findings in general examination are shown in table 1.

Table 1: Mean values of main parameters of general examination of the population study $(n=150)$.

\begin{tabular}{|l|c|}
\hline \multicolumn{1}{|c|}{ Parameter } & Mean \pm SD \\
\hline Systolic blood pressure $(\mathbf{m m ~ H g})$ & $\mathbf{1 2 8 . 8 3} \pm 19.37$ \\
\hline Diastolic blood pressure $(\mathrm{mm} \mathrm{Hg})$ & $\mathbf{8 2 . 1 3} \pm \mathbf{1 5 . 5 3}$ \\
\hline Weight $(\mathrm{kg})$ & $\mathbf{7 9 . 9 3} \pm \mathbf{1 4 . 2 5}$ \\
\hline Height $(\mathrm{cm})$ & $\mathbf{1 6 0 . 6 4} \pm 7.57$ \\
\hline Waist circumference $(\mathrm{cm})$ & $\mathbf{1 0 9 . 7 8} \pm \mathbf{1 7 . 5 6}$ \\
\hline Body mass index $\left(\mathrm{kg} / \mathrm{m}^{2}\right)$ & $\mathbf{3 1 . 0 6} \pm \mathbf{5 . 7 2}$ \\
\hline
\end{tabular}

The mean values of DAS28 and its different components are shown in table 2. Categories of disease activity in the study population according to DAS28 are demonstrated in table 3.The CRP was positive in 136 (90.7\%) of the study population, with median value of $12 \mathrm{mg} / \mathrm{L}$ (IQR: 8-25 mg/L). The RF was positive in $97(64.7 \%)$ of the study population, with median value of $36 \mathrm{IU} / \mathrm{ml}$ (IQR: $8-128 \mathrm{IU} / \mathrm{ml}$ ). The anti-CCP was positive in $99(66 \%)$ of the study population. The mean \pm SD level of FBG was $86.53 \pm 28.75 \mathrm{mg} / \mathrm{dl}$.The mean \pm SD level of TG was $124.64 \pm 39.55 \mathrm{mg} / \mathrm{dl}$, TC was $193.02 \pm 42.42 \mathrm{mg} / \mathrm{dl}$, and HDL-C was $46.7 \pm 8.81 \mathrm{mg} / \mathrm{dl}$. 
Table 2: Mean values of DAS28 and its different components in the study population ( $\mathrm{n}=$ 150).

\begin{tabular}{|l|l|}
\hline \multicolumn{1}{|c|}{ Parameter } & \multicolumn{1}{c|}{ Mean \pm SD } \\
\hline Number of tender joints & $\mathbf{5 . 5 3} \pm \mathbf{3 . 8 8}$ \\
\hline Number of swollen joints & $\mathbf{2 . 2 3} \pm \mathbf{2 . 5 8}$ \\
\hline erythrocyte sedimentation rate & $\mathbf{5 0 . 8 9} \pm \mathbf{2 7 . 0 3}$ \\
\hline visual analogue scale (VAS 0-100) & $\mathbf{5 1 . 0 5} \pm \mathbf{2 5 . 5 8}$ \\
\hline DAS-28 & $\mathbf{4 . 9 0} \pm \mathbf{1 . 2 2}$ \\
\hline
\end{tabular}

Table 3: Categories of disease activity in the study population $(n=150)$ according to DAS28.

\begin{tabular}{|l|c|}
\hline \multicolumn{1}{|c|}{ Parameter } & Frequency (Percentage) \\
\hline RA in remission (DAS $<2.6)$ & $\mathbf{4}(\mathbf{2 . 7 \%})$ \\
\hline Low disease activity (DAS 2.6-3.2) & $\mathbf{1 3}(\mathbf{8 . 7 \%})$ \\
\hline Moderate disease activity (DAS 3.2-5.1) & $\mathbf{5 5 ( 3 6 . 7 \% )}$ \\
\hline High disease activity (DAS >5.1) & $\mathbf{7 8 ( 5 2 \% )}$ \\
\hline
\end{tabular}

MetS diagnostic criteria in the study population were met in $72(48 \%), 78(52 \%)$, and 69 (46\%) according to ATPIII (2004), IDF (2005), and JIS with Egyptian cut-off values of WC (2009), respectively. The prevalence of each parameter is shown in table 4.

Table 4: Prevalence of metabolic syndrome parameters in the study population $(n=150)$.

\begin{tabular}{|c|c|c|c|}
\hline Parameter & ATPIII (2004) & IDF (2005) & JIS (2009) \\
\hline Central obesity & $126(84 \%)$ & $138(92 \%)$ & $113(75.3 \%)$ \\
\hline Raised BP or hypertension & $81(54 \%)$ & $81(54 \%)$ & $81(54 \%)$ \\
\hline Raised TG & $38(25.3 \%)$ & $38(25.3 \%)$ & $38(25.3 \%)$ \\
\hline Decreased HDL-C & $85(56.7 \%)$ & $85(56.7 \%)$ & $85(56.7 \%)$ \\
\hline Raised FBG or T2D & $36(24 \%)$ & $36(24 \%)$ & $36(24 \%)$ \\
\hline
\end{tabular}

The study population was divided according to the presence of MetS (JIS definition with Egyptian cut-off values of WC) into two groups: RA patients with MetS ( $n=69)$ and RA patients without MetS $(n=81)$. The demographic data of the study groups are shown in table 5.The arthritis history and therapeutic history of the study groups are shown in table 6 .

Table 5: Demographic data of the study groups according to presence of MetS (JIS, 2009).

\begin{tabular}{|c|c|c|c|}
\hline Parameter & $\begin{array}{c}\text { Rheumatoid patients without } \\
\text { MetS }(n=81)\end{array}$ & $\begin{array}{c}\text { Rheumatoid patients with } \\
\text { MetS }(n=69)\end{array}$ & * $\mathbf{P}$ value \\
\hline Age $($ Mean \pm SD $)$ & $42.7 \pm 12.1$ & $47.7 \pm 9.1$ & 0.004 \\
\hline \multicolumn{4}{|l|}{ Sex } \\
\hline Male & $19(23.5 \%)$ & $5(7.2 \%)$ & \multirow[t]{2}{*}{0.007} \\
\hline Female & $62(76.5 \%)$ & $64(92.8 \%)$ & \\
\hline \multicolumn{4}{|l|}{ Residence } \\
\hline Urban & $27(33.3 \%)$ & $21(30.4 \%)$ & \multirow[t]{2}{*}{0.72} \\
\hline Rural & $54(66.7 \%)$ & $47(69.6 \%)$ & \\
\hline \multicolumn{4}{|l|}{ Occupation } \\
\hline Housewife & $62(76.5 \%)$ & $50(61.7 \%)$ & \multirow[t]{4}{*}{0.62} \\
\hline Farmer & $7(8.7 \%)$ & $5(6.2 \%)$ & \\
\hline Worker & $4(4.9 \%)$ & $4(5.8 \%)$ & \\
\hline Employee & $8(9.9 \%)$ & $10(12.3 \%)$ & \\
\hline Smoking & $13(16.0 \%)$ & $4(5.8 \%)$ & 0.07 \\
\hline
\end{tabular}


Table 6: Arthritis history and therapeutic history of the study groups according to presence of MetS (JIS, 2009).

\begin{tabular}{|c|c|c|c|c|}
\hline & Parameter & $\begin{array}{l}\text { Rheumatoid patients } \\
\text { without MetS }(n=81)\end{array}$ & $\begin{array}{c}\text { Rheumatoid patients with } \\
\text { MetS }(n=69)\end{array}$ & * $\mathbf{P}$ value \\
\hline & $\begin{array}{l}\text { se at disease onset in } \\
\text { years }(\text { Mean } \pm \text { SD) }\end{array}$ & $33.40 \pm 10.69$ & $38.32 \pm 9.93$ & 0.004 \\
\hline & $\begin{array}{l}\text { ease durationin years } \\
\quad(\text { Mean } \pm \text { SD) }\end{array}$ & $9.60 \pm 8.01$ & $9.59 \pm 6.96$ & 0.96 \\
\hline & No & $46(56.8 \%)$ & $27(39.1 \%)$ & 0.17 \\
\hline & 5 minutes & $1(1.2 \%)$ & $4(5.8 \%)$ & \\
\hline 告 & 10 minutes & $2(2.5 \%)$ & $1(1.4 \%)$ & \\
\hline 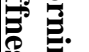 & 15 minutes & $1(1.2 \%)$ & $\mathbf{0}$ & \\
\hline & 30 minutes & $6(7.4 \%)$ & $8(11.6 \%)$ & \\
\hline & $\geq 60$ minutes & $25(30.9 \%)$ & $29(42 \%)$ & \\
\hline & $\begin{array}{l}\text { Non-steroidal anti- } \\
\text { flammatory drugs }\end{array}$ & $79(97.5 \%)$ & $67(97.1 \%)$ & 0.63 \\
\hline & Steriods & $30(37 \%)$ & $31(44.9 \%)$ & 0.51 \\
\hline & Methotrexate & $56(69.14 \%)$ & $50(72.46 \%)$ & 0.24 \\
\hline & ydroxychloroquine & $64(79 \%)$ & $48(69.6 \%)$ & 0.19 \\
\hline & Sulfasalazine & $20(24.7 \%)$ & $11(15.9 \%)$ & 0.32 \\
\hline & Leflunomide & $24(29.6 \%)$ & $22(31.9 \%)$ & 0.86 \\
\hline
\end{tabular}

Comparison of the main findings in the general examination in the study groups are shown in table 7.The DAS28 parameters inthe study groups are shown in table 8. Categories of disease activity in the study groups according to DAS28 are shown in table 9.Comparison of the immunological investigations in the study groups are shown in table 10.

Table 7: Comparison of main findings in the general examination in the study groups according to presence of MetS (JIS, 2009).

\begin{tabular}{|c|c|c|c|}
\hline \multirow{2}{*}{ Parameter } & $\begin{array}{c}\text { Rheumatoid patients } \\
\text { without MetS }(\mathbf{n}=\mathbf{8 1})\end{array}$ & $\begin{array}{c}\text { Rheumatoid patients with } \\
\text { MetS }(\mathbf{n = 6 9})\end{array}$ & \multirow{2}{*}{ P value } \\
\cline { 2 - 3 } & \multicolumn{2}{|c|}{ Mean \pm SD } & \\
\hline Systolic BP $(\mathbf{m m H g})$ & $\mathbf{1 2 0 . 2 5} \pm \mathbf{1 6 . 0 4}$ & $\mathbf{1 3 8 . 9 1} \pm \mathbf{1 8 . 1 3}$ & $<\mathbf{0 . 0 0 1}$ \\
\hline Diastolic BP $(\mathbf{m m H g})$ & $\mathbf{7 6 . 1 7} \pm \mathbf{1 4 . 2 8}$ & $\mathbf{8 9 . 1 3} \pm \mathbf{1 4 . 0 1}$ & $<\mathbf{0 . 0 0 1}$ \\
\hline Weight $(\mathbf{k g})$ & $\mathbf{7 5 . 2 5} \pm \mathbf{1 3 . 7 2}$ & $\mathbf{8 5 . 4 2} \pm \mathbf{1 2 . 9 1}$ & $<\mathbf{0 . 0 0 1}$ \\
\hline Height $(\mathbf{m})$ & $\mathbf{1 . 6 1} \pm \mathbf{0 . 7 9}$ & $\mathbf{1 . 6 0} \pm \mathbf{0 . 7 1}$ & $\mathbf{0 . 3 1}$ \\
\hline WC & $\mathbf{1 0 3 . 1 5} \pm \mathbf{1 7 . 9 3}$ & $\mathbf{1 1 7 . 5 7} \pm \mathbf{1 3 . 5 5}$ & $<\mathbf{0 . 0 0 1}$ \\
\hline BMI $\left(\mathbf{k g} / \mathbf{m}^{2}\right)$ & $\mathbf{2 9 . 0 2} \pm \mathbf{5 . 5 1}$ & $\mathbf{3 3 . 4 5} \pm \mathbf{5 . 0 3}$ & $<\mathbf{0 . 0 0 1}$ \\
\hline BP: blood pressure; WC: Waist circumference; BMI: body mass index. & \\
\hline
\end{tabular}

$* \mathrm{P}$ value $<0.05$ was significant.

Table 8: Comparison of DAS28 parameters in the study groups according to presence of MetS.

\begin{tabular}{|c|c|c|c|}
\hline \multirow[t]{2}{*}{ Parameter } & $\begin{array}{l}\text { Rheumatoid patients } \\
\text { without MetS }(n=81)\end{array}$ & $\begin{array}{c}\text { Rheumatoid patients } \\
\text { with MetS }(n=69)\end{array}$ & \multirow[t]{2}{*}{ * P value } \\
\hline & \multicolumn{2}{|c|}{ Mean \pm SD } & \\
\hline Number of tender joints & $4.86 \pm 3.70$ & $6.32 \pm 3.96$ & $\mathbf{0 . 0 2}$ \\
\hline Number of swollen joints & $1.98 \pm 2.55$ & $2.54 \pm 2.60$ & 0.16 \\
\hline ESR & $48.64 \pm 27.71$ & $53.53 \pm 26.18$ & 0.27 \\
\hline VAS 0-100 & $46.38 \pm 25.46$ & $56.52 \pm 24.78$ & 0.02 \\
\hline DAS-28 & $4.65 \pm 1.19$ & $5.18 \pm 1.19$ & 0.008 \\
\hline
\end{tabular}

$* \mathrm{P}$ value $<0.05$ was significant. 
Table 9: Comparison of disease activity categories in the study groups according to presence of MetS (JIS, 2009).

\begin{tabular}{|c|c|c|c|}
\hline Parameter & $\begin{array}{l}\text { Rheumatoid patients } \\
\text { without MetS }(n=81)\end{array}$ & $\begin{array}{l}\text { Rheumatoid patients } \\
\text { with MetS }(n=69)\end{array}$ & * $\mathbf{P}$ value \\
\hline RA in remission (DAS < 2.6) & $3(3.7 \%)$ & $1(1.4 \%)$ & \multirow[t]{4}{*}{$<0.001$} \\
\hline Low disease activity (DAS 2.6-3.2) & $6(7.4 \%)$ & $7(10.1 \%)$ & \\
\hline $\begin{array}{l}\text { Moderate disease activity (DAS 3.2- } \\
\text { 5.1) }\end{array}$ & $41(50.6 \%)$ & $14(20.3 \%)$ & \\
\hline High disease activity $($ DAS $>5.1)$ & $31(38.3 \%)$ & $47(68.1 \%)$ & \\
\hline
\end{tabular}

Table 10: Comparison of the immunological investigations in the study groups according to presence of MetS (JIS, 2009).

\begin{tabular}{|c|c|c|c|}
\hline Parameter & $\begin{array}{c}\text { Rheumatoid patients } \\
\text { without MetS }(\mathbf{n = ~ 8 1})\end{array}$ & $\begin{array}{c}\text { Rheumatoid patients } \\
\text { with MetS }(\mathbf{n}=\mathbf{6 9})\end{array}$ & $*$ P value \\
\hline C-reactive protein & $\mathbf{7 4}(\mathbf{9 1 . 4} \%)$ & $\mathbf{6 2}(\mathbf{8 9 . 9} \%)$ & $\mathbf{0 . 7 8}$ \\
\hline Erythrocyte sedimentation rate & $\mathbf{4 8 . 6 4} \pm \mathbf{2 7 . 7 1}$ & $\mathbf{5 3 . 5 3} \pm \mathbf{2 6 . 1 8}$ & $\mathbf{0 . 2 7}$ \\
\hline Rheumatoid factor & $\mathbf{5 2}(64.2 \%)$ & $\mathbf{4 5}(65.2 \%)$ & $\mathbf{0 . 5 2}$ \\
\hline Anti-cyclic citrullinated peptides & $\mathbf{5 2}(64.2 \%)$ & $\mathbf{4 7}(68.1 \%)$ & $\mathbf{0 . 3 7}$ \\
\hline
\end{tabular}

$* \mathrm{P}$ value $<0.05$ was significant.

\section{DISCUSSION}

In the current study; most patients were females $(84 \%)$ with mean age $45.01 \pm 11.05$ years and disease DAS28. This may be explained by the setting from which they were recruited (a tertiary-level referral hospital) and no use of biological theray in any of the patients.

In this study the prevalence of MetS in RA patients was $48 \%$ (ATPIII definition), $52 \%$ (IDF definition), and $46 \%$ (JIS definition with Egyptian cutoff), respectively. This was higher than that reported in a previous study on 3209 randomly selected Egyptian population; $42.5 \%$ (ATPIII definition), $44.3 \%$ (IDF definition), and $41.5 \%$ (JIS definition with Egyptian cut-off), respectively ${ }^{(17)}$. This indicates that presence of RA may increase possibility of presence of MetS.

This prevalence was near that previously reported in RA patients; $51.4 \%$ (ATPIII) and $53.4 \%$ (IDF definition) in 107 Brazilian rheumatoid patients ${ }^{(18)}$, and a recent Brazilian report of $50.3 \%$ (ATPIII) ${ }^{(19)}$. However; this was lower than previous Italian study that reported $55.5 \%$ duration $9.60 \pm 7.35$ years. More than half of patients $(52 \%)$ had severe disease activity according to (25/45) (ATP III) ${ }^{(20)}$. The reported prevalence in the current study is one of the highest prevalences all over the world.

On the contrary; this prevalence was higher than that previously reported in RA patients; $40.1 \%$ (ATPIII) and 45.4 $\%$ (IDF) in 387 British rheumatoid patients ${ }^{(21)}, 25.5 \%$ (ATPIII) of 98 rheumatoid patients in Portugal (22), $32.4 \%$ (ATPIII), $40.9 \%$ (IDF), and $32.4 \%$ (JIS) of 105 patients from Vietnam $^{(23)}, 10.6 \%$ (53/499; IDF) in American patients ${ }^{(24)}, 42.6 \%(23 / 54$; IDF) in Turkey ${ }^{(25)}, 36.4 \%$ (59/162; ATPIII) in American patients ${ }^{(\mathbf{2 6})}, 30 \%$ (ATPIII), and $35 \%$ (IDF) of 409 Argentinan patients (27), and $38 \%$ (ATPIII), 48.6 (IDF), and $32.3 \%$ (JIS) in Morocco ${ }^{(28)}$. The difference in prevalence may be related to ethnicity, geographic area, nutritional habits, and different inclusion criteria and disease characteristics.

In this study the most prevalent component of MetS was central 
obesity (75.3- $92 \%$ according to the used definition) and was more common in females; while the lowest prevalence was high FBG (17.3-24 \%). The highest prevalence of obesity was according to IDF definition (92\%: $94 \%$ in females, $75 \%$ in males), followed by ATPIII definition (84\%: $89.9 \%$ in females, $54.2 \%$ in males), and JIS definition with Egyptian cutoff $(75.3 \%: 79.6 \%$ in females, $54.2 \%$ in males). This may indicate the use of Egyptian WC cutoffs to avoid the overestimated prevalence of abdominal obesity resulting from European cutoffs ${ }^{(17)}$.

These results were also higher than that was previously reported in Greek rheumatoid patients with central obesity (ATPIII) in $74.8 \%(110 / 147)$ in female patients and $60.4 \%(32 / 53)$ in male patients ${ }^{(11)}$. Lower prevalence was also reported in Pakistan with central obesity (ATPIII) in $46.1 \%$ of 384 rheumatoid patients ${ }^{(29)}$. This may be related to the socioeconomic, lifestyle, and nutritional changes which have been occurring in the Egyptian community; towards the unhealthy pattern.

In the current study; patients with Mets were significantly older than those without MetS. This was in accordance with previous reports ${ }^{(8,19,30-32)}$. This may be related to the fact that age is a variable known to increase the frequency of comorbidities, MetS among them. In this study; the age of disease onset was significantly higher in patients with MetS with no significant difference of disease duration. This was in accordance with previous reports $(\mathbf{8}, \mathbf{1 0}, \mathbf{1 9}, 27)$. This enforces the value of age of patients over the disease duration in development of MetS.On the other side; other studies reported longer duration of RA in rheumatoid patients with MetS (11, 23, 30). This may be related to different age groups, duration of the disease, and the used drugs in these studies.

In the present study; there was no statistically significant difference between RA patients with and without MetS as regards used NSAIDs, steroids and DMARDs. This was in accordance with previous reports $(\mathbf{8}, \mathbf{1 9}, \mathbf{3 2})$. On the contrary; a previous study showed a significant association between the absence of MetS and the use of MTX and suggested the possibility of a drugspecific protection mechanism for MTX (21). This may be explained by that; in the current study; the use of NSAIDs and glucocorticoids may have compensated for the protective effect of MTX and hydroxychloroquine.

In the current study; DAS28 was significantly higher in patients with MetS with higher number of tender joints and VAS (0-100). This was in accordance with previous reports ${ }^{(8,19}$, 30). On the opposite side; a previous study failed to confirm this finding ${ }^{(33)}$. The authors explained their findings that the aggressive treatment with DMARDs and life style modifications may alter MetS prevalence. In the present study; most RA patients with MetS (68\%) had high disease activity. This was in accordance with previous studies $(19,34,35)$. This suggests that inflammation could play a role in the development of metabolic disturbance in RA patients.

In the present study; there was no statistically significant difference between rheumatoid patients with and without MetS as regards immunological investigations (CRP, $\mathrm{RF}$, and anti-CCP). This was in accordance with previous reports ${ }^{(8,11 \text {, }}$ 19, 28). On the contrary; higher ESR and CRP were found in RA patients with MetS ${ }^{(30)}$. This can be explained that the RA patients in the last study were treatment naïve.

In the current study; hypertension and use of antihypertensive drugs was 
reported in $28(18.7 \%)$ of the patients. However; elevated BP was found in higher proportion $(54 \%)$. This was in accordance with previous reports of high prevalence of raised BP in RA ${ }^{(11}$, 36, 37). Moreover; Panoulas et al. (2007) reported that hypertension is underdiagnosed, especially in young RA patients. This indicates the value of follow up of BP in rheumatoid patients to detect hypertension early and avoid development of CVDs.

None of the rheumatoid patients in this study was treated for dyslipidemia. However; raised TG was found in 38 $(25.3 \%)$ of patients and decreased HDL-C was detected in 85 (56.7\%) of the patients. The increased levels of dyslipidemia in RA patients were previously reported ${ }^{(11,38,39)}$. A recent study reported high prevalence of undiagnosed hypercholesterolemia in patients with RA ${ }^{(40)}$. These findings demonstrate the importance of searching for dyslipidemias in rheumatoid patients in order to decrease CVD events and all-cause mortality.

In the present study; only 19 (12.7\%) of the patients had DM; while raised FBG was found in 36 (24\%) of the patients. This was in accordance with previous reports ${ }^{(\mathbf{8}, 31)}$. A recent study demonstrated that impaired FBG was a strong predictor of T2D after one year of follow up in rheumatoid patients ${ }^{(41)}$. This finding indicates the importance of studying impaired FBG in rheumatoid patients to avoid further development of T2D.

Despite interesting findings of this study, it was limited by its crosssectional design not allowing conducting any cause-effect inferences on relationship between RA characteristics and MetS. A longitudinal study should be designed to establish the casualty of these findings. Another limitation is the risk of selection bias since our center is a tertiary referral center with recruitment of mostly active and severe disease patients, and potentially leading to an overestimation of the prevalence of MetS. Multicenter studies with larger number of rheumatoid patients are warranted in order to determine prevalence of MetS in Egyptian patients with RA.

\section{REFERENCES}

1. Smolen JS, Aletaha D and Mcinnes IB: Rheumatoid arthritis.Lancet. 2016; 388(10055): 2023-2038.

2. Silman AJ and Pearson JE: Epidemiology and genetics of rheumatoid arthritis.Arthritis Res. 2002; 4 Suppl 3: S265-72.

3. Kramer HR and Giles JT: Cardiovascular disease risk in rheumatoid arthritis: progress, debate, and opportunity.Arthritis Care Res (Hoboken). 2011; 63(4): 484-99.

4. Lopez-Mejias R, Castaneda S, Gonzalez-Juanatey C, Corrales A, Ferraz-Amaro I: Cardiovascular risk assessment in patients with rheumatoid arthritis: The relevance of clinical, genetic and serological markers.Autoimmun Rev. 2016; 15(11): 1013-1030.

5. Rochlani Y, Pothineni NV, Kovelamudi S and Mehta JL: Metabolic syndrome: pathophysiology, management, and modulation by natural compounds.Ther Adv Cardiovasc Dis. 2017: 1753944717711379.

6. Tune JD, Goodwill AG, Sassoon DJ and Mather KJ: Cardiovascular consequences of metabolic syndrome.Transl Res. 2017; 183: 57-70.

7. Zhang J, Fu L, Shi J, Chen X, Li Y: The risk of metabolic syndrome in patients with rheumatoid arthritis: a meta-analysis of observational studies.PLoS One. 2013; 8(10): e78151.

8. Parra-Salcedo F, Contreras-Yanez I, Elias-Lopez D, Aguilar-Salinas CA and Pascual-Ramos V: Prevalence, incidence and characteristics of the metabolic 
syndrome (MetS) in a cohort of Mexican Mestizo early rheumatoid arthritis patients treated with conventional disease modifying anti-rheumatic drugs: the complex relationship between MetS and disease activity.Arthritis Res Ther. 2015; 17: 34

9. Kerekes G, Nurmohamed MT, Gonzalez-Gay MA, Seres I, Paragh G: Rheumatoid arthritis and metabolic syndrome.Nat Rev Rheumatol. 2014; 10(11): 691-6.

10. Lee SG, Kim JM, Lee SH, Kim KH, Kim JH: Is the frequency of metabolic syndrome higher in South Korean women with rheumatoid arthritis than in healthy subjects? Korean J Intern Med. 2013; 28(2): 206-15.

11. Karvounaris SA, Sidiropoulos PI, Papadakis JA, Spanakis EK, Bertsias GK: Metabolic syndrome is common among middle-to-older aged Mediterranean patients with rheumatoid arthritis and correlates with disease activity: a retrospective, cross-sectional, controlled, study.Ann Rheum Dis. 2007; 66(1): 28-33.

12. Aletaha D, Neogi $T$, Silman AJ, Funovits J, Felson DT: 2010 rheumatoid arthritis classification criteria: an American College of Rheumatology/European League Against Rheumatism collaborative initiative.Ann Rheum Dis. 2010; 69(9): 1580-8.

13. Jung YO and Kim HA: Recent paradigm shifts in the diagnosis and treatment of rheumatoid arthritis.Korean J Intern Med. 2012; 27(4): 378-87.

14. Grundy SM, Brewer HB, Cleeman JI, Smith SC and Lenfant C: Definition of metabolic syndrome: Report of the National Heart, Lung, and Blood Institute/American Heart Association conference on scientific issues related to definition.Circulation. 2004; 109(3): 4338.

15. Alberti KG, Zimmet $P$ and Shaw J: Metabolic syndrome--a new world-wide definition. A Consensus Statement from the International Diabetes
Federation.Diabet Med. 2006; 23(5): 46980.

16. Alberti KG, Eckel RH, Grundy SM, Zimmet PZ, Cleeman JI: Harmonizing the metabolic syndrome: a joint interim statement of the International Diabetes Federation Task Force on Epidemiology and Prevention; National Heart, Lung, and Blood Institute; American Heart Association; World Heart Federation; International Atherosclerosis Society; and International Association for the Study of Obesity.Circulation. 2009; 120(16): 16405 .

17. Assaad-Khalil SH, Mikhail MM, Aati TA, Zaki A, Helmy MA: Optimal waist circumference cutoff points for the determination of abdominal obesity and detection of cardiovascular risk factors among adult Egyptian population.Indian $\mathbf{J}$ Endocrinol Metab. 2015; 19(6): 804-10.

18. De Oliveira BM, Medeiros MM, De Cerqueira JV, De Souza Quixada RT and De Oliveira IM: Metabolic syndrome in patients with rheumatoid arthritis followed at a University Hospital in Northeastern Brazil.Rev Bras Reumatol Engl Ed. 2016; 56(2): 117-25.

19. Gomes KWP, Luz AJP, Felipe MRB, Beltrao LA, Sampaio AXC: Prevalence of metabolic syndrome in rheumatoid arthritis patients from Northeastern Brazil: Association with disease activity.Mod Rheumatol. 2017: 1-6.

20. La Montagna G, Cacciapuoti F, Buono R, Manzella D, Mennillo GA: Insulin resistance is an independent risk factor for atherosclerosis in rheumatoid arthritis.Diab Vasc Dis Res. 2007; 4(2): 130-5.

21. Toms TE, Panoulas VF, John H, Douglas KM and Kitas GD: Methotrexate therapy associates with reduced prevalence of the metabolic syndrome in rheumatoid arthritis patients over the age of 60- more than just an antiinflammatory effect? A cross sectional study.Arthritis Res Ther. 2009; 11(4): R110 
22. Santos MJ, Vinagre F, Silva JJ, Gil $\mathrm{V}$ and Fonseca JE: Cardiovascular risk profile in systemic lupus erythematosus and rheumatoid arthritis: a comparative study of female patients.Acta Reumatol Port. 2010; 35(3): 325-32.

\section{Dao HH, Do QT and Sakamoto J:} Increased frequency of metabolic syndrome among Vietnamese women with early rheumatoid arthritis: a crosssectional study.Arthritis Res Ther. 2010; 12(6): R218.

24. Baker JF, Mehta NN, Baker DG, Toedter G, Shults J: Vitamin D, metabolic dyslipidemia, and metabolic syndrome in rheumatoid arthritis.Am $\mathrm{J}$ Med. 2012; 125(10): 1036 e9-1036 e15.

25. Karakoc M, Batmaz I, Sariyildiz MA, Tahtasiz M, Cevik R: The relationship of metabolic syndrome with disease activity and the functional status in patients with rheumatoid arthritis.J Clin Med Res. 2012; 4(4): 279-85.

26. Ormseth MJ, Lipson A, Alexopoulos N, Hartlage GR, Oeser AM: Association of epicardial adipose tissue with cardiometabolic risk and metabolic syndrome in patients with rheumatoid arthritis.Arthritis Care Res (Hoboken). 2013; 65(9): 1410-5.

27. Salinas MJ, Bertoli AM, Lema L, Saucedo C, Rosa J: Prevalence and correlates of metabolic syndrome in patients with rheumatoid arthritis in Argentina.J Clin Rheumatol. 2013; 19(8): 439-43.

28. Rostom S, Mengat M, Lahlou R, Hari A, Bahiri R: Metabolic syndrome in rheumatoid arthritis: case control study.BMC Musculoskelet Disord. 2013; 14: 147 .

29. Zafar ZA, Mahmud TH, Rasheed A and Wagan AA: Frequency of metabolic syndrome in Pakistani cohort of patients with rheumatoid arthritis.J Pak Med Assoc. 2016; 66(6): 671-6.

30. Pandey PK, Swami A, Biswas TK and Thakuria R: Prevalence of metabolic syndrome in treatment naive rheumatoid arthritis and correlation with disease
parameters.Arch Rheumatol. 2017; 32(1): 46-52.

31. Goshayeshi L, Saber H, Sahebari M, Rezaieyazdi Z, Rafatpanah H: Association between metabolic syndrome, BMI, and serum vitamin D concentrations in rheumatoid arthritis.Clin Rheumatol. 2012; 31(8): 1197-203.

32. Da Cunha VR, Brenol CV, Brenol JC, Fuchs SC, Arlindo EM: Metabolic syndrome prevalence is increased in rheumatoid arthritis patients and is associated with disease activity.Scand $\mathbf{J}$ Rheumatol. 2012; 41(3): 186-91.

\section{Sahebari M, Goshayeshi L, Mirfeizi} Z, Rezaieyazdi Z, Hatef MR: Investigation of the association between metabolic syndrome and disease activity in rheumatoid arthritis.Scientific World J. 2011; 11: 1195-205.

34. Chung CP, Oeser A, Solus JF, Avalos I, Gebretsadik T: Prevalence of the metabolic syndrome is increased in rheumatoid arthritis and is associated with coronary atherosclerosis.Atherosclerosis. 2008; 196(2): 756-63.

35. Abourazzak FE, Mansouri S, Najdi A, Tahiri L, Nejjari C: Prevalence of metabolic syndrome in patients with rheumatoid arthritis in Morocco: a crosssectional study of 179 cases.Clin Rheumatol. 2014; 33(11): 1549-55.

36. Panoulas VF, Douglas KM, Milionis HJ, Stavropoulos-Kalinglou A, Nightingale P: Prevalence and associations of hypertension and its control in patients with rheumatoid arthritis.Rheumatology (Oxford). 2007; 46(9): 1477-82.

37. Bajraktari IH, Rexhepi S, Berisha I, Lahu A, Kryeziu A: Prevalence of Asymptomatic Arterial Hypertension and Its Correlation with Inflammatory Activity in Early Rheumatoid Arthritis.Open Access Maced J Med Sci. 2017; 5(5): 641644.

38. Erum U, Ahsan T and Khowaja D: Lipid abnormalities in patients with 
Rheumatoid Arthritis.Pak J Med Sci. 2017; 33(1): 227-230.

39. Galarza-Delgado DA, Azpiri-Lopez JR, Colunga-Pedraza IJ, Cardenas-De La Garza JA, Vera-Pineda R: Prevalence of comorbidities in Mexican mestizo patients with rheumatoid arthritis.Rheumatol Int. 2017.

40. Van Breukelen-Van Der Stoep DF, Van Zeben D, Klop B, Van De Geijn GJ, Janssen HJ: Marked underdiagnosis and undertreatment of hypertension and hypercholesterolaemia in rheumatoid arthritis.Rheumatology (Oxford). 2016; 55(7): 1210-6.

41. Ruscitti $P$, Ursini F, Cipriani $P$, Liakouli V, Carubbi F: Poor clinical response in rheumatoid arthritis is the main risk factor for diabetes development in the short-term: A 1-year, single-centre, longitudinal study.PLoS One. 2017; 12(7): e0181203. 